\title{
Validating human decision making in an agent-based land-use model
}

\author{
$\underline{\text { Grace B. Villamor }}^{\text {ab }}$, Klaus G. Troitzsch ${ }^{\mathrm{c}}$, and Meine van Noordwijk ${ }^{\mathrm{b}}$ \\ ${ }^{a}$ Center for Development Research (ZEF), University of Bonn, Germany; ${ }^{b}$ World Agroforestry Center \\ (ICRAF), Bogor, Indonesia; ${ }^{c}$ Institute of Informatics Systems in Business and Public Administration, \\ University of Koblenz-Landau, Germany
}

Email: gracev@uni-bonn.de

\begin{abstract}
Validation of agents' decision making is one of the central epistemological problems in empirical agent-based model (ABM) simulations. This paper focuses on the need for reliable decisionmaking models for land change science with direct relevance to modelling human-environmental systems for policy implications and natural resources management. This paper presents a set of key issues or caveats that affect the validation. At the same time, we present alternatives by providing examples of a more stakeholdercentric way of parameterizing human behaviour and decision making, and a case study is described in the light of critical multiplism.
\end{abstract}

Keywords: Land-use change; validation; human decision making; stakeholder participation; critical multiplism 


\section{INTRODUCTION}

In natural resource management, the agent-based modelling ( $\mathrm{ABM}$ ) approach is currently seen as promising in the integration of various knowledge systems, as it explicitly incorporates the decision making of various actors. In fact, the ability to explicitly simulate the implications of human decision-making processes is claimed to be the main strength (Parker et al., 2003; Matthews et al. 2007; Smajgl et al., 2011; Villamor et al., 2011). However, most current agent-based models operate, often implicitly, at the micro-economic scale of cost-benefit analysis and assumed rationality of net benefit maximization and ignore other influences. Such models can, however, incorporate richer and more holistic decision modules, adding value to a purely empirical trend-extrapolation approach. Conversely, any claim to understand and represent human decision making beyond extrapolation of past trends is more easily made than implemented and verified (van Noordwijk et al., 2012). This paper focuses on the empirical parameterization of human decision-making processes and how it threatens the validation of decision-making sub-models in agent-based models. The first section of this paper describes the caveats and pitfalls of empirical modelling of human decision making that go beyond extrapolation of historic trends. Three of the four caveats are adapted from Villamor et al. (2012). The next section presents alternative approaches for validating human decision making in the light of critical multiplism (Pierce 1934/1960). The final section presents a case study showing parameterization methods that facilitate validation of agents' behaviour and decisions.

\section{CAVEATS AND PITFALLS OF EMPIRICAL MODELING}

\subsection{Causal relationship and missing confounder}

In the context of land-use change studies, for instance, micro-economic analysis suggests that a farm household deciding whether to expand its farm plot will consider various factors such as the expected market price and attainable yields of crops and the required investment of its labour. With a wide range of possible choices, the household will assess the utility of each of the choices relative to its current asset base. The utility values are then transformed into choice probabilities. Statistical tools (i.e., logistic regression) are used to calculate probabilities and correlate particular actor attributes with recent land-use decisions either reported in a survey or observed from remotely sensed imagery (Evan et al., 2006). However, Kahnemann (2011) specifically pointed out that incorrect causal interpretations of regression effects, i.e., confusing mere correlation with causation, are not restricted to the popular press but are a common source of trouble in research. Moreover, there are confounders that explain or produce all or parts of the difference between the measure of association and the measure of effect that would be obtained with counterfactual ideals. According to Freedman (2010), it would be better to rely on subject-matter expertise, and to exploit natural variation to mitigate confounding and rule out competing explanations.

\subsection{Drawing causal inferences from cross-sectional data}

Due to the difficulty in collecting empirical data, the researchers have to rely on the data from cross-sectional surveys. Cross-sectional data are used to estimate parameters of functional forms of agents' decisions or other relations of variables. In most cases, the justification for the selected variables used in the model is that they are available, reasonably cheap and a good fit with the data. Generally, cross-sectional data are snapshots and the decision whether we observed a punctuated, temporary equilibrium or a stasis cannot be made by merely using one observation in time. Therefore, using only one point in time, or an observation period that is short relative to the typical system dynamics, we cannot be sure whether parameters or functional forms are stable in time. The functional form could also be incomplete to produce reliable results from interpolation if relevant confounders are not accounted for. In principle, this unavoidable drawback of using an observational study could only be solved either by using an experimental study or practically by using subject matter's knowledge to justify the functional form (Villamor et al. 2012).

\subsection{Functional form as a compressed description}

In using a functional form as a compressed description, initially we have a sample that determines $\mathrm{n}$ points in a k-dimensional interval built by the extremes of the $\mathrm{k}$ variables (sample intervals). Then we could decide to use either (i) only those points observed as starting values for a new simulation step (bootstrap approach), or (ii) start with points from very small spheres around each observed point (adding noise approach), or (iii) use any point within the sample interval (interpolation). It seems that if we use decent functions in our model and stay in the sample interval in any of the three forms above we should be safe. However, leaving the sample interval and extrapolating might lead to overshooting, heavy oscillations or generally to unrealistic constellations. For example, we might assume that a sample domain has indicated or forced a simple form 
(e.g., linear) where a sigmoid relation would be more appropriate. In such a case, leaving the sample interval would clearly lead to unrealistic overshoots or lower deviates.

\subsection{Weak theoretical representations of human decision making and behaviour}

Theoretical frameworks and paradigms exist for decision making to describe and explore human behaviour and decision making (Kennedy 2012; Meyfroidt 2012; van Noordwijk et al., 2012). However, due to the nature and complexity of the human mind, the progress on the scientific study of how humans behave could be said to be slow (Kennedy 2012). There are two scientific approaches of modelling human behaviour being developed, 1) Artificial Intelligence (AI) using mathematical approaches and 2) Cognitive Science through all forms of human cognition that includes emotions, intuition and motivations. Both of their methods and techniques are useful in modelling human decisions and behaviours. However, the full implementations of these available frameworks and paradigms to explicitly show various active forces of landscape changes are very limited in empirical ABM models (Meyfroidt 2012) while theoretical representations of human decision making are still weak (Heckbert et al., 2010).

These caveats are fundamental and often ignored in the modelling processes especially if the nature of the research problem that is being tackled by the modelling exercises has policy implications. They are among the many factors that threaten the validation of decision-making models. In the following section, examples of validation techniques engaging stakeholders are presented as alternative.

\section{STAKEHOLDER-CENTRIC VALIDATION}

Validation denotes the establishment of legitimacy (Oreskes et al., 1994). Legitimacy, for most modellers, refers to the intention and agenda of the tool developers as perceived by stakeholders (Lusiana et al., 2011). Hence, the agreement of participants or stakeholders with the model or simulation, particularly regarding the rules and behaviour, can be an indicator of the validity of a simulation model (Troitzsch 2004). The following are current examples of this kind of validation, which enhance the saliency, credibility and legitimacy of decision-making models (Cash et al., 2003).

\subsection{Companion modelling (COMMOD)}

In COMMOD, the multi-agent system model is calibrated and verified through involvement of stakeholders through role-playing games and direct interviews. Over repeated interactions between stakeholders and modellers, the objects and rules that make up the software are more closely mapped onto the target system. Repeated examination of the fit between the model and target system makes model failures more apparent; verification and structural validation are therefore more easily achieved (Bousquet et al., 2003). Using this approach, Moss (2008) described an important aspect in the validation exercise. This is the precision with respect to the process of computational modelling in which the multi-agent model is programmed based on the accounts given by the stakeholders. According to Moss (2008), it is an example of Curry-Howard isomorphism, i.e., a logical proof of being precise. Moreover, the methodological issues of empirical validation inherent to theory-driven models are unimportant or irrelevant if the purpose of modelling is for policy and strategy discussion.

\subsection{Open Collaboration for Policy Modelling (OCOPOMO)}

These types of ABM models are specifically for policy modelling and patterned from companion modelling through the use of role-playing games (RPGs). The difference in this platform when compared to COMMOD is that stakeholders are involved in both policy modelling/scenario generation and analysis sessions. Accordingly, the ABM modellers become facilitators whose role it is to help the stakeholders to restate verbal statements and implicit assumptions that arise in narrative scenarios as precise statements of conditions and consequences of actions under those conditions (Moss et al., 2011). These statements are formalized as if-then rules, which are used to determine the software agent's behaviour representing the various stakeholders. The OCOPOMO process consists of seven steps which are briefly described below (Moss et al., 2011): (1) develop scenarios of the outcomes from various policy initiatives suggested by the stakeholders; (2) transform scenarios in a formal way to guide the stakeholders in identifying gaps in the reasoning, and making their assumptions more precise; (3) develop conceptual description which comprises an ontology defining the relevant entities (i.e., actors, social entities, physical objects, abstract concepts) and their relationships, and which in turn informs the specification of agent types, fact bases and rule bases; (4) transform into formal model where visualization is involved so that stakeholders can easily understand it; (5) 
develop simulation model (visualization tools are also used); (6) run simulation that produces outputs (e.g., model-based scenario text, statistical data, etc.); and (7) evaluation and validation with stakeholders.

\subsection{Salience-credibility-legitimacy (SLC) framework}

The salience-credibility-legitimacy framework (Cash et al., 2003) was used to validate a model by direct users and relevant stakeholders. In this framework, credibility involves the scientific adequacy of the technical evidence and arguments, salience deals with the relevance of the assessment to the needs of decision makers, and legitimacy reflects the perception that the production of information and technology has been respectful of stakeholders' diligent values and beliefs, unbiased in its conduct, and fair in its treatment of opposing views and interests. Lusiana et al. (2011) translated these attributes to validate simulation models as shown in Table 1. The results of the application of this framework suggest that salience is a more important attribute than having perfect models that only answer irrelevant questions with limited use for the beneficiaries or stakeholders.
Table 1. Application of Salience-credibility-legitimacy framework to model validation

\begin{tabular}{|c|c|}
\hline Criteria & Simulation model attributes \\
\hline \multirow{3}{*}{$\begin{array}{l}\text { Salience (relevancy of the } \\
\text { model to lead to real } \\
\text { changes in identified } \\
\text { problems) }\end{array}$} & $\begin{array}{l}\text { Useful and applicable outputs } \\
\text { for natural resource } \\
\text { management }\end{array}$ \\
\hline & $\begin{array}{l}\text { Clear and understandable } \\
\text { theory and processes }\end{array}$ \\
\hline & Easy to use and parameterize \\
\hline $\begin{array}{l}\text { Credibility (entails } \\
\text { perceptions by users that } \\
\text { the concepts and }\end{array}$ & $\begin{array}{l}\text { Outputs have similar patterns } \\
\text { to those observed in the field }\end{array}$ \\
\hline $\begin{array}{l}\text { processes in the model } \\
\text { are acceptable as a } \\
\text { approximation of } \\
\text { reality) }\end{array}$ & $\begin{array}{l}\text { Attractive and easy-to- } \\
\text { understand outputs }\end{array}$ \\
\hline $\begin{array}{l}\text { Legitimacy (intention and } \\
\text { agenda of the tool } \\
\text { developers as perceived } \\
\text { by stakeholders) }\end{array}$ & $\begin{array}{l}\text { Developed by well known } \\
\text { scientists with stakeholder } \\
\text { involvement } \\
\text { Has been used by policy } \\
\text { makers }\end{array}$ \\
\hline
\end{tabular}

\subsection{Convergent validity through mixed-methods approach}

Summer and MacKay (1977) define convergent validity as an assessment of the degree of agreement between the results of maximally different methods for measuring the same construct. Accordingly, it is typically used when there is no acceptable single method to serve as an absolute valid standard for measuring the construct of interest. This notion evolved from the concept of scientific convergence by Pierce (1934/1960) following the philosophy of critical multiplism that encourages the use of multiple sources of data and research techniques (or triangulation). It seeks to reaffirm and strengthen the validity of, and users' confidence in empirical work. Accordingly, mixing methods (both quantitative and qualitative) or convergence acts as a cable for linking various arguments and evidence ( $\mathrm{Yu}$ 2003). The target is not to validate each method; rather the different results yielded from various methods should be retained so that a more complete picture of the phenomenon under investigation can be seen (Jick 1983). The next section presents a case study using an approach similar to companion modelling where convergent validity is explored.

\section{CASE STUDY}

\subsection{Study area}

The study area comprises the three villages Lubuk Beringin, Laman Panjang, and Desa Buat located in Jambi Province (Sumatra), Indonesia. It covers a total area of $16 \mathrm{~km}^{2}$ near the foothills of Kerinci Seblat National Park. Rubber agroforest was once the dominant land use in the province, and is still the major rural livelihood of the people living there; rice field is the main food source. However, due to the low latex productivity from these agroforests, farmers are now forced to convert their farm lands into more profitable land uses such as oil palm and monoculture rubber plantations. On the other hand, conservation agencies and local NGOs value rubber agroforest for its function as refugia for lowland forest diversity and climate change mitigation.

\subsection{Empirical parameterization: human behaviour}

The study employed two major parameterization techniques, i.e., household survey and land-use RPG. The aim of the household survey was to determine if the households would maintain their existing rubber agroforest if they received rewards from payments for ecosystem services (PES) scheme or whether they would like to change their existing land use to a more profitable land-use option if given financial subsidies. In the household survey, two household typologies were identified and characterized, namely 1) rubber-rice based, and 2) rubber agroforest based (Villamor, 2012). In each household type, land-use choice and willingness to participate in PES were estimated using multinomial and binary logistic regressions and the resulting models were embedded in the decision-making procedure of the LB-LUDAS model - an agent- 
based land-use model where the biophysical system (including its attributes) of the study site interacts with the social system (Villamor, 2012).

For the land-use RPG, the willing respondents from the survey played the roles of farmers and external agents promoting either of land conversion or conservation. Land-use game boards presenting the major land-use types of the target landscape were given to the farmers for them to visualize and operate preferred land uses. Similar to the research questions raised in the survey questionnaire, the farmers would change the land-use types in the game board based on their negotiations with different buyers promoting either conversion or conservation (i.e., oil palm company, logging concession, green rubber company, conservation NGO, and government programs). Play money was provided in the game together with score sheets to monitor how they achieved their income targets (Villamor and van Noordwijk, 2011). The land-use RPG is considered as a model representing the landscape of the target study area played by 'real' farmers. The results of the game were used to refine and adjust the agent behaviour in the LB-LUDAS model, e.g., farmers' perception of different land uses.

\subsection{Convergence of model constructs}

According to Summer and MacKay (1977), if the results of the two completely different independent methods are in close agreement, both are said to share establishment of convergent validity. The land-use pattern observed under a PES scenario simulated from the ABM was apparently in agreement with the results of the land-use game board simulated from the RPG (Figure 1). In Figure 1a, the land-use map of 2005 is the baseline, and after simulation at years 10 and 20 only minimal changes can be observed. In comparison with the RPG simulation, there is no apparent land-use change except in the case of the natural burnt areas that are part of the game setting (see Villamor and van Noordwijk, 2011). At the same time, rubber monoculture was not accepted during the game negotiation, thus no rubber emerged in the land-use game board while a reduced of rubber monoculture was observed in the ABM simulation. These two different methods share the same model construct in terms of problem formulation and model details (Table 1 and Figure 2). The main theoretical framework of both methods is based on the concept of emergence - resulting from local or simple interaction. Both methods assessed the emergent property (i.e., land-use pattern) based on the interactions of a) agents in the ABM, and b) actors/players in the land-use RPG (for details of results of both methods see Villamor, 2012; and Villamor van Noordwijk, 2011).

According to Bousquet and LePage (2004), the use of several techniques and methods of ABM may enhance the credibility of the model, which is the principle of critical multiplism (Pierce, 1934/1960) and one of the pillars of the SLC framework (Cash et al., 2003). At the same time, the use of mixed models allows assessing the convergent validity of the two models (i.e., ABM and land-use RPG) (Figure 2). Moreover, it was observed during the modelling exercise, that the land-use RPG provided rich behaviours of household agents that are not captured by the household survey (Villamor and van Noordwijk, 2011). Instead, the decision rules used for the LB-LUDAS model were refined using the results of the RPG, since the players are the 'real actors or farmers' living in the target study site.
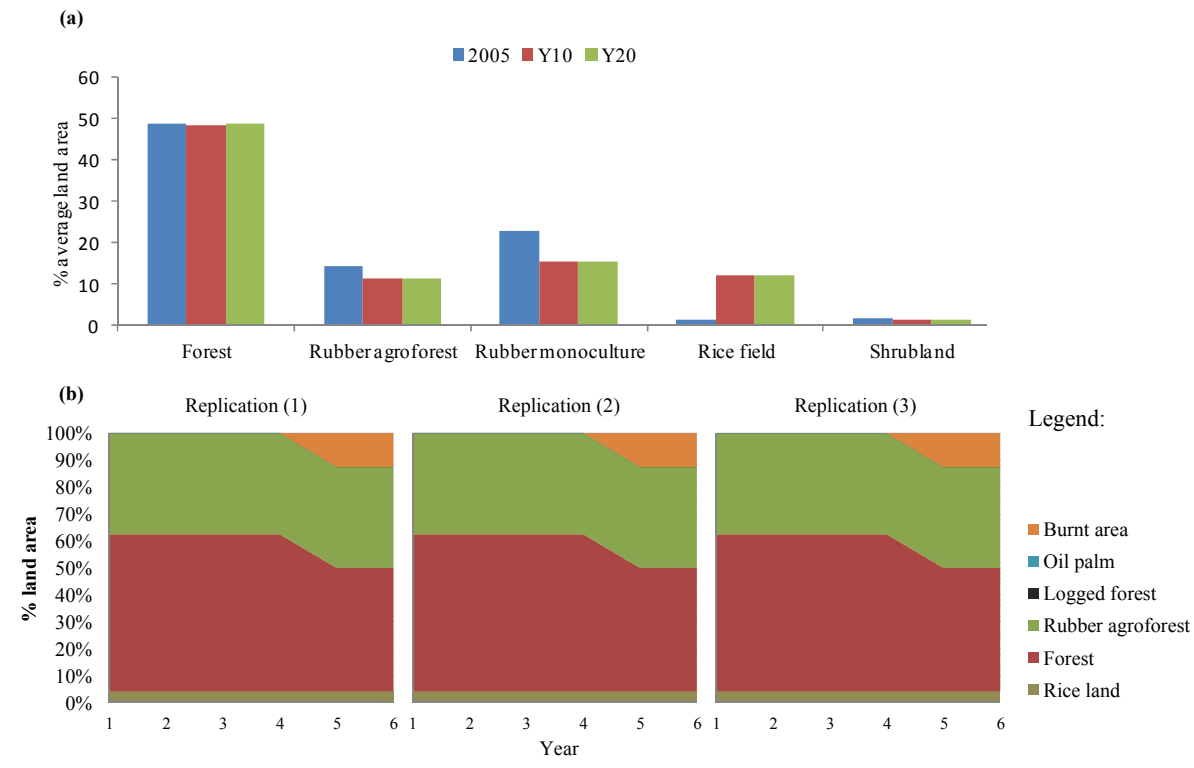

Figure 1. Example of land-use pattern based on two methods a) agent-based model simulation (i.e., LBLUDAS; Villamor, 2012), and b) land-use RPG (Villamor and van Noordwijk 2011) 
Villamor et al., Validating human decision making in an agent-based land use model

Table 2. Summary of two model constructs for convergent validity

\begin{tabular}{|c|c|c|}
\hline \multirow{2}{*}{$\begin{array}{c}\text { Research (method) process } \\
\text { (i.e., construct) }\end{array}$} & \multicolumn{2}{|c|}{ Models } \\
\hline & $\begin{array}{l}\text { (1) Agent-based land-use model (i.e., LB- } \\
\text { LUDAS model; Villamor, 2012) }\end{array}$ & $\begin{array}{l}\text { (2) Land-use role-playing games (Villamor } \\
\text { and van Noordwijk, 2011; Villamor et al., } \\
\text { 2013) }\end{array}$ \\
\hline Problem formulation & $\begin{array}{l}\text { Household agents' decision to change land uses } \\
\text { under two scenarios: } \\
\begin{array}{l}\text { 1) if provided with financial incentives } \\
\text { 2) willingness to adopt payments for } \\
\text { ecosystem services }\end{array}\end{array}$ & $\begin{array}{l}\text { Social response to actors of conversion or } \\
\text { conservation of rubber agroforests in Sumatra, } \\
\text { Indonesia. } \\
\text { To determine if households will convert their } \\
\text { existing rubber agroforest to oil palm or other } \\
\text { monoculture plantation under payments for } \\
\text { ecosystem services (PES) scenario }\end{array}$ \\
\hline Theoretical concept & $\begin{array}{l}\text { Land-use pattern is the emergent property from } \\
\text { households' interaction }\end{array}$ & $\begin{array}{l}\text { Land-use pattern is the emergent property from } \\
\text { households interaction }\end{array}$ \\
\hline \multicolumn{3}{|l|}{ Model details } \\
\hline (a) Environment & 2005 land-use map of the study area & $\begin{array}{l}\text { Land-use game board with major land-use } \\
\text { composition (i.e., forest, rubber agroforest, } \\
\text { monoculture rubber, rice fields, and settlement } \\
\text { area) }\end{array}$ \\
\hline (b) Agents/Actors & $\begin{array}{l}95 \text { surveyed households with individual } \\
\text { attributes }\end{array}$ & $28 \%$ of the 95 surveyed households \\
\hline (c) Rules & $\begin{array}{l}\text { Land-use choices under the following scenarios: } \\
\begin{aligned} \text { 3) if provided with financial incentives } \\
\text { 4) willingness to adopt payments for } \\
\text { ecosystem services }\end{aligned}\end{array}$ & $\begin{array}{l}\text { To sustain and enhance the living standard of } \\
\text { the villagers, an income target must be } \\
\text { achieved through negotiation with different } \\
\text { actors }\end{array}$ \\
\hline Mode of analysis & Landscape level using computer simulations & $\begin{array}{l}\text { Landscape level (i.e., village level) using game } \\
\text { boards simulated with real-life agents (i.e., } \\
\text { farmers) }\end{array}$ \\
\hline (a) Parameter & $\begin{array}{l}\text { Population increase }(1.4 \% ; 2003 \text { Statistical } \\
\text { Record) }\end{array}$ & Population increase of $20 \%$ \\
\hline \multirow[t]{2}{*}{ Result/output } & Land-use change & Land-use change \\
\hline & $\begin{array}{l}\text { a) Pattern (Figure 1a) } \\
\text { b) } \text { Frequency of transition }\end{array}$ & a) Pattern (Figure 1b) \\
\hline
\end{tabular}

Since a land-use RPG is a quasi-experimental tool for parameterizing human behaviour, we do not have to worry about the missing confounders and causality, which are the main problems in a cross-sectional household survey. However, the specific activities and detailed differences in the land-use RPG (i.e., time scales and resolution) are not discussed in this paper, rather the focus is to find means to validate the representation of human decision making in ABM through stakeholder-centric approach.

\section{CONCLUSIONS}

This paper discusses the caveats of decision-making models that threaten the empirical validation of ABM land-use simulation. In fact, empirical validation of agents' decision making remains one of the central epistemological problems in the empirical agent-based model simulations. For this reason, we argue that 1) the involvement of the 'real actors' from the target system in any parameterization technique would better capture the behaviour of the households while increasing the credibility and legitimacy of the ABM simulation results, thus making the modelling exercise more salient and legitimate for the modeller and the end users and suggesting sound policy recommendations for natural

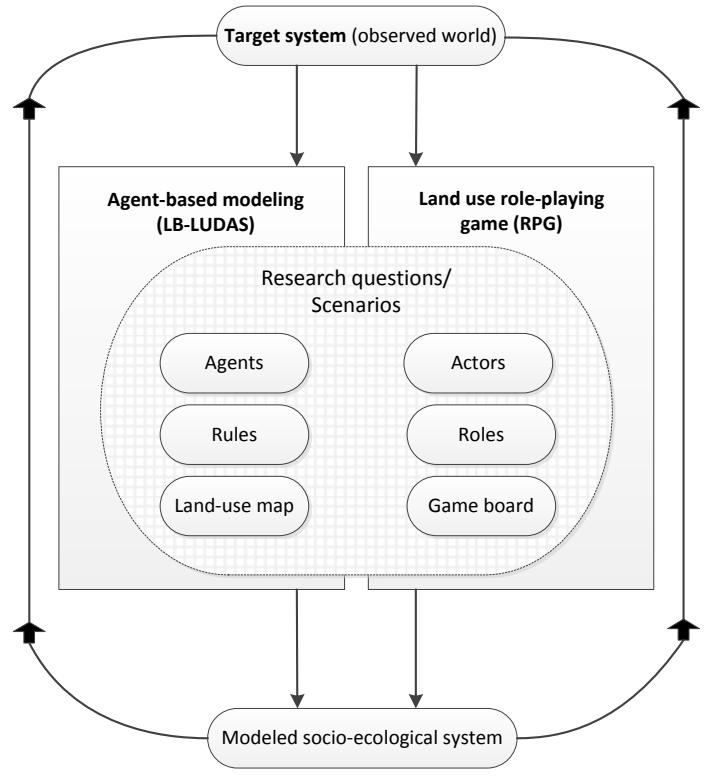

Figure 2. Following the concept of Summer and McKay (1977), the two models share the same model constructs that support convergent validity. resource management; 2) the concept of critical multiplism reaffirms and strengthens the validity of empirical work via convergence of results from multiples methods (in this case ABM land-use simulation and land-use RPG), theoretical orientations, and perspectives; and 3) different methods through critical multiplism could assess the plausibility of identified threats to validity and enhances the interpretability of a phenomenon (Mark and Shotland, 1987). 
Villamor et al., Validating human decision making in an agent-based land use model

\section{ACKNOWLEDGEMENTS}

We thank Guido Lüchters for the valuable comments and suggestions on the earlier version of this paper.

\section{REFERENCES}

Bousquet, F., Barreteau, O., Aquino (d'), P., Etienne, M., Boissau, S., Aubert, S., Le Page, C., Babin, D., and J.-C. Castella (2003). Multi-agentsystems and role games: collective learning processes for ecosystem management. In: M. Janssen (Ed.), Complexity and Ecosystem Management: The Theory and Practice of Multi-Agent Approaches. Edward Elgar Publishers, pp. 248-285.

Cash, D.W., Clark, W.C., Alcock, F., Dickson, N.M., Eckley, N., Guston, D.H., Jäger, J., and R.B. Mitchell (2003). Knowledge systems for sustainable development. Proceedings of the National Academy of Sciences, 100, 80868091.

Evans, T.P., Sun, W., and H. Kelley (2006). Spatially explicit experiments for the exploration of land-use decisionmaking dynamics. International Journal of Geographical Information Science, 20, 1013-1037.

Freedman, D.A. (2010). Statistical models and causal inference. Cambridge University Press, Cambridge.

Heckbert, S., Baynes, T., and A. Reeson (2010). Agent-based modelling in ecological economics. Annals of the New York Academy of Sciences, 1185, 39-53.

Jick, T. (1983). Mixing qualitative and quantitative methods: triangulation in action, In van Mennen (Ed) Qualitative methodology. Beverly Hills, CA: Sage Publications, pp. 135-148.

Kahnemann, D. (2011). Thinking, fast and slow. London: Penguin.

Kennedy, W.G. (2012). Modelling human behavior in agent-based models. In A.J. Heppenstall, A.T. Crooks, \& L.M. See (Eds) Agent-Based Models of Geographical Systems (pp.167-179) Springer, Dordrecht, Heidelberg, London, New York.

Lusiana, B., van Noordwijk, M., Suyamto, D.A., Mulia, R., Joshi, L., and G. Cadisch (2011). Users' perspectives on validity of a simulation model for natural resource management. International Journal of Agricultural Sustainability, 9, 363-378.

Mark, M.M., and R.L. Shotland (1987). Alternative models for the use of multiple methods. In M.M. Mark and RL. Shotland (Eds). Multiple methods in program evaluation: New Directions for Program Evaluation 35 (pp. 95 100). San Francisco: Jossey-Bass.

Matthews, R., Gilbert, N., Roach, A., Polhill, J., and N. Gotts (2007). Agent-based land-use models: a review of applications. Landscape Ecology, 22, 1447-1459.

Meyfroidt, P. (2012). Environmental cognition, land change, and social-ecological feedbacks: an overview. Journal of Land Use Science, doi:10.1080/1747423X.2012.667452.

Moss, S. (2008). Alternative approaches to empirical validation of agent-based models. Journal of Articifial Societies and Social Simulations, 11, http://jasss.soc.surrey.ac.uk/11/11/15.html.

Moss, S. (2011). Policy modelling, open collaboration and the future of e-governance.

Oreskes, N., Shrader-Frechette, K., and K. Belitz (1994). Verification, Validation, and Confirmation of Numerical Models in the Earth Sciences. Science, 263, 641-646.

Parker, D.C., Manson, S.M., Janssen, M.A., Hoffmann, M.J., and P.J. Deadman (2003). Multi-Agent Systems for the Simulation of Land-Use and Land-Cover Change: A Review. Annals of the Association of American Geographers, 93, 314-337.

Pierce, C.S. (1934/1960). Collected papers of Charles Sanders Peirce. Cambridge: Harvard University Press.

Smajgl, A., Brown, D.G., Valbuena, D., and M. Huigen (2011). Empirical characterisation of agent behaviours in socioecological systems. Environmental Modelling \& Software, 26, 837-844.

Summer, J.O., and D.B. MacKay (1977). On establishing convergent validity: a reply to Wilkes and Wilcox. Journal of Marketing Research, 14(4), 263-265.

Troitzsch, K.G. (2004).Validating simulation models, Proceedings of the 18th European Simualtion Multi-Conference, pp.98-106.

van Noordwijk, M., Leimona, B., Jindal, R., Villamor, G.B., Vardhan, M., Namirembe, S., Catacutan, D., Kerr, J., Minang, P.A., and T.P. Tomich (2012). Payments for Environmental Services: evolution toward efficient and fair incentives for multifunctional landscapes. Annual Review of Environment and Resources, 37

Villamor, G.B. (2012). Flexibility of multi-agent system models for rubber agroforest landscapes and social response to emerging reward mechanisms for ecosystem services in Sumatra, Indonesia. Ecology and Development Series No. 88. University of Bonn, Germany, 181p.

Villamor, G.B., and M. van Noordwijk (2011). Social Role-Play Games Vs Individual Perceptions of Conservation and PES Agreements for Maintaining Rubber Agroforests in Jambi (Sumatra), Indonesia. Ecology and Society, 6 (3), 27.

Villamor, G.B., van Noordwijk, M., Troitzsch, K.G., and P.L.G. Vlek (2012). Human decision making in empirical agent-based models: pitfalls and caveats for land-use/change policies. In: K.G. Troitzsch, M. Möhring, \& U. Lotzmann (Eds.): Proceedings 26th European Conference on Modelling and Simulation. ECMS, http://dx.doi.org/10.7148/2012, pp.631-638.

Villamor, G.B., van Noordwijk, M., Le, Q.B., Lusiana, B., Matthews, R. and PL.G. Vlek. (2011). Diversity deficits in modelled landscape. Ecological Informatics, 6(1): 73-82. 